\title{
ISÓTOPOS ESTÁVEIS E OUTRAS FERRAMENTAS EM ESTUDOS TRÓFICOS DE PEIXES EM RIACHOS TROPICAIS
}

\author{
Míriam Pilz Albrecht ${ }^{1 *}$, Andressa da Silva Reis², Vinicius Neres-Lima ${ }^{3}$,Eugenia Zandonà ${ }^{3}$ \\ ${ }^{1}$ Universidade Federal do Rio de Janeiro, Instituto de Biologia, Departamento de Ecologia, Laboratório de Ecologia \\ de Peixes, CP 68020, Ilha do Fundão, CEP 21941-902, Rio de Janeiro, RJ, Brasil. \\ ${ }^{2}$ Universidade Vila Velha, Tropical Water Research Alliance, Rua Comissário José Dantas de Melo, 21 Boa Vista, CEP \\ 29102-920, Vila Velha, ES, Brasil. \\ ${ }^{3}$ Universidade do Estado do Rio de Janeiro, Departamento de Ecologia, Rua São Francisco Xavier 524, Maracanã, CEP \\ 20550-013, Rio de Janeiro, RJ, Brasil. \\ E-mails: albrechtmp@gmail.com (*autora correspondente); asreis.bio@gmail.com; vinicius.lima.eco@gmail.com; \\ eugenia.zandona@gmail.com.
}

\begin{abstract}
Resumo: A análise de isótopos estáveis (AIE) se tornou uma ferramenta essencial na Ecologia, sendo cada vez mais utilizada em estudos de peixes de riachos tropicais. A AIE permite reconstruir a dieta dos animais e suas variações intraespecíficas, traçar as contribuições dos principais recursos basais que sustentam as teias tróficas, calcular a posição trófica e o nicho trófico, incluindo partilha e alterações de nicho, e construir teias tróficas. A AIE é amplamente utilizada também para entender o impacto de alterações ambientais nas comunidades de peixes e de outros organismos aquáticos. O número de estudos é crescente no Brasil, porém ainda há diversas lacunas. Neste artigo, apresentamos conceitos básicos sobre a análise de isótopos estáveis em estudos tróficos de peixes de riacho, especialmente de carbono, nitrogênio e hidrogênio, suas premissas, usos e limitações, permeando com exemplos em riachos tropicais. Exploramos também novas fronteiras para estudos nessa área, ainda não utilizadas para peixes de riacho no Brasil, como análise de ácidos graxos, análise de isótopos estáveis em compostos específicos, geometria nutricional e conceitos da estequiometria ecológica tais como o Limiar de Proporções de Elementos.
\end{abstract}

Palavras-chave: assimilação de recursos; fluxo de energia; nicho isotópico; posição trófica, ácidos graxos.

STABLE ISOTOPES AND OTHER TOOLS IN TROPHIC STUDIES OF TROPICAL STREAM FISH: Stable isotope analysis (SIA) has become an essential tool in Ecology, being increasingly used in studies of fish in tropical streams. The SIA allows to reconstruct the animals' diet and its intraspecific variation, to trace the contributions of the main basal resources throughout the food web, to calculate trophic position and trophic niche, including niche overlap and its alterations, and to build food webs. The SIA is also used to understand the impact of environmental changes on fish communities and other aquatic organisms. The number of such studies is increasing in Brazil, but there are still several gaps. In this study, we present the basic concepts on stable isotopes analysis in trophic studies of stream fish - especially those of carbon, nitrogen and hydrogen - their assumptions, uses and limitations, presenting examples from tropical streams. We also explore new conceptual tools in this area, still not used for stream fish in Brazil, such as fatty acids, stable isotopes in specific compounds, nutritional geometry and ecological stoichiometry concepts such as the Threshold Elemental Ratio.

Keywords: resources assimilation; energy flow; isotopic niche; trophic position; fatty acids. 


\section{INTRODUÇÃO}

Desde que as pesquisas sobre ecologia trófica passaram a enfatizar também a assimilação de recursos, especialmente pelo advento do uso de traçadores bioquímicos, tornou-se mais claro que a qualidade dos recursos deveria ser tão ou mais importante do que a sua quantidade para a eficiência do fluxo de energia nas teias tróficas de riachos e para a determinação do papel trófico dos consumidores. Nos últimos anos, novas ferramentaspermitiramavançosnoconhecimento e levantamento de novas hipóteses nestes aspectos da ecologia da fauna aquática, como análises de isótopos estáveis (AIE) de carbono, nitrogênio (Fry 2006) e hidrogênio (Doucett et al. 2007), bem como AIE em compostos específicos (Whiteman et al. 2019), análise de ácidos graxos (Guo et al. 2016), estequiometria ecológica (Zandonà et al. 2021) e geometria nutricional (Simpson \& Raubenheimer 2012). Embora apenas a AIE tenha se tornado usual em estudos de peixes de riacho no Brasil, podemos dizer que a incorporação dessas novas técnicas é promissora e desejável, uma vez que adicionam acurácia aos demais métodos e permitem a elaboração de novas perguntas.

A AIE emergiu como uma ferramenta chave para os ecólogos e o número de estudos, especialmente relacionados à ecologia trófica, cresceu exponencialmente nos últimos anos (Shipley \& Matich 2020). Tem se mostrado fundamental na reconstrução da dieta dos animais (Zandonà et al. 2017) e suas variações intraespecíficas (Bearhop et al 2004), na resposta a alterações ambientais (Layman et al. 2007b), na elucidação dos principais recursos basais que sustentam as teias tróficas (Brito et al. 2006, Neres-Lima et al. 2016, Reis et al. 2020), no cálculo da posição trófica (Post 2002, Reis et al. 2020), no entendimento do nicho trófico, incluindo partilha e alterações de nicho (Carvalho et al. 2019), na caracterização das interações tróficas dentro de populações e comunidades (Layman et al. 2007a) e na construção de teias tróficas (Neres-Lima et al. 2017). Cada uma dessas aplicações trata de vias de fluxo de energia que interligam um ou mais consumidores a seus recursos alimentares dentro de um contexto ecológico de interações intra e interespecíficas.

A utilidade da AIE em estudos tróficos baseia- se no princípio de que composição isotópica de vários materiais, incluindo os tecidos dos organismos, contêm uma "marca" dos processos metabólicos que os originaram, podendo ser utilizada como biomarcadores naturais. Os isótopos são intrínsecos ao ambiente físico e são incorporados nos tecidos dos produtores primários durante o processo fotossintético e subsequentemente transferidos para os animais que as consomem (Fry 2006) (Quadro 1). Isótopos estáveis de diversos elementos têm sido utilizados em estudos ecológicos, especialmente aqueles que estão presentes em todos os organismos vivos, como carbono $(\mathrm{C})$, nitrogênio $(\mathrm{N})$, oxigênio $(\mathrm{O})$, hidrogênio (H) e enxofre (S) (Fry 2006).

Neste capítulo, apresentamos conceitos básicos sobre a análise de isótopos estáveis em estudos de peixes de riacho, especialmente de carbono, nitrogênio e hidrogênio, suas premissas, usos e limitações, permeando com estudos de caso que utilizam essas ferramentas para estudos tróficos e de transferência de energia em riachos tropicais, priorizando aqueles em riachos brasileiros. Exploramos também novas fronteiras para estudos nessa área, ainda não utilizadas para peixes de riacho no Brasil, como análises de ácidos graxos, análise de isótopos estáveis em compostos específicos e geometria nutricional.

\section{ASPECTOS METODOLÓGICOS}

O fluxo de energia representa a transferência de energia desde a captação por organismos autotróficos até a sua dissipação por respiração heterotrófica. Exceto em estudos sobre orçamento de energia (energy budget), que expressam os fluxos através de massa ou energia por área por unidade de tempo (por exemplo, $\mathrm{g} \mathrm{m}^{-2} \mathrm{y}^{-1}$ ), a maior parte dos estudos tróficos baseiam-se em medidas como a proporção dos recursos alimentares consumidos (Análise de Conteúdo Estomacal ACE) ou assimilados (Análise de Isótopos Estáveis - AIE). Outras abordagens metodológicas que apresentamos são ferramentas alternativas e/ ou complementares para estudos tróficos de assimilação de recursos.

Os isótopos estáveis (Quadro 1) de carbono, nitrogênio e hidrogênio têm sido os mais frequentemente utilizados em estudos de fluxo de energia e ecologia trófica de peixes em riachos. 
Para essa análise, são necessárias coletas dos peixes e dos seus potenciais recursos alimentares, além de amostra de água no caso das análises de isótopos de hidrogênio, pois parte desse elemento incorporado nos tecidos dos consumidores é proveniente da dieta, mas uma outra parte é proveniente da água. As coletas são seguidas de procedimentos específicos em campo e laboratório para posterior quantificação (Quadro 2). As terminologias empregadas e interpretação geral dos resultados podem ser encontradas no Quadro 3.

\section{Fontes basais de energia}

Ao reunir os valores isotópicos de $\delta^{13} \mathrm{C}, \delta^{15} \mathrm{~N}$ e $\delta^{2} \mathrm{H}$ dos peixes e de seus recursos potenciais, podemos

Quadro 1. Isótopos estáveis.

Box 1. Stable isotopes.

Átomos de mesmo número atômico, mas diferentes pesos atômicos são denominados isótopos. A maioria dos elementos de interesse biológico, que são encontrados em todos os seres vivos, possuem dois ou mais isótopos estáveis, com os mais leves presentes em abundância muito maior ( 99 \%). Isótopos de um mesmo elemento fazem parte das mesmas reações químicas, porém, uma vez que possuem pesos atômicos diferentes, reagem em taxas diferentes, resultando em produtos de reação que são isotopicamente mais pesados ou mais leves do que os seus materiais precursores. As plantas C3 fracionam o carbono diferentemente das plantas C4, então as diferentes razões de carbono pesado/ carbono leve (13C/ 12C) resultantes podem ser usadas para distinguir produtores primários com diferentes metabolismos. Os tecidos de animais consumidores, por sua vez, refletem as razões isotópicas dos produtores primários dos quais se alimentam e que são assimilados em seus tecidos.

Quadro 2. Coleta, procedimentos de laboratório e análise.

Box 2. Data gathering, lab procedures and analysis.

Em cada riacho, a coleta de peixes e de seus recursos alimentares devem ser feitas, preferencialmente, no mesmo dia, já que pode haver variações isotópicas diariamente dos recursos. Para AIE em riachos é essencial a coleta de recursos basais, ou seja, os produtores primários tanto autóctones, como perifíton e macrófitas, quanto alóctones, como folhiço e folhas frescas (C3 e C4). Dependendo do estudo e da dieta potencial da espécie de peixe, outros recursos alimentares devem ser coletados, como matéria orgânica particulada e os macroinvertebrados. A coleta desses recursos pode ser qualitativa ou quantitativa, dependendo dos objetivos do estudo. Amostradores do tipo Loeb para coleta do perifíton (Moulton et al. 2009), Surber ou core para coleta dos macroinvertebrados e matéria orgânica particulada bentônica podem ser utilizados para as coletas quantitativas, isto é, por unidade de área. Uma vez que o álcool e, principalmente, o formol podem alterar a razão isotópica das amostras, convém não fixá-las, mas sim congelá-las ou processá-las imediatamente. O perifíton é composto por algas, bactérias, fungos, outros microrganismos e matéria orgânica sedimentada, então pode ser necessário fazer a separação de algas do restante deste material por centrifugação da amostra em sílica coloidal (Hamilton et al. 2005) para se obter uma amostra mais pura em algas. Contudo, o valor isotópico de organismos pastadores obrigatórios podem ser utilizados como proxy (substituto) dos valores isotópicos de algas após a correção do FET (Neres-Lima et al. 2017).

Os peixes devem ser dissecados para retirada de amostra do tecido. Geralmente utiliza-se partes do tecido muscular (tecidos distintos têm diferentes taxas de reposição, consequentemente refletem diferentes tempos de assimilação de recursos). No caso de tecidos com alto teor de lipídios, pode ser necessária sua extração ou utilização de correções matemáticas, já que os lipídios podem enviesar os valores de 13C. Geralmente, amostras do corpo inteiro dos macroinvertebrados são utilizadas para as análises de isótopos estáveis, mas o conteúdo do trato digestório desses organismos deve ser evitado, deixando o animal em jejum, esvaziando o trato ou removendo o trato por dissecção.

As amostras dos consumidores e recursos, após secas e maceradas até virar um pó homogêneo, são transferidas para cápsulas de estanho e pesadas em balança de precisão para serem analisadas quanto às suas composições isotópicas em um espectrômetro de massas de fluxo contínuo acoplado a um analisador elementar. As amostras de peso conhecido são então inseridas no aparelho e incineradas até se transformarem em um gás. O gás é ionizado em um filamento quente e os diferentes íons que formam esse gás são guiados, dependendo da sua massa ou carga, para diferentes coletores através de um ímã. Se um íon é mais leve, é desviado primeiro para seu coletor. Um software acoplado ao aparelho distingue as proporções de átomos leves e pesados e então calcula a composição isotópica. 
construir a teia trófica do riacho, traçando as relações tróficas interespecíficas a partir da determinação dos principais recursos assimilados e as posições tróficas dos diferentes consumidores. Recursos terrestres, como invertebrados, folhas e frutos, podem ser diretamente consumidos pelos peixes ou indiretamente através do consumo de invertebrados ou da matéria orgânica que entra na cadeia de detritivoria (Figura 1).

Uma das principais diferenças entre recursos basais autóctones (perifíton) e alóctones (plantas terrestres) é sua qualidade nutricional enquanto

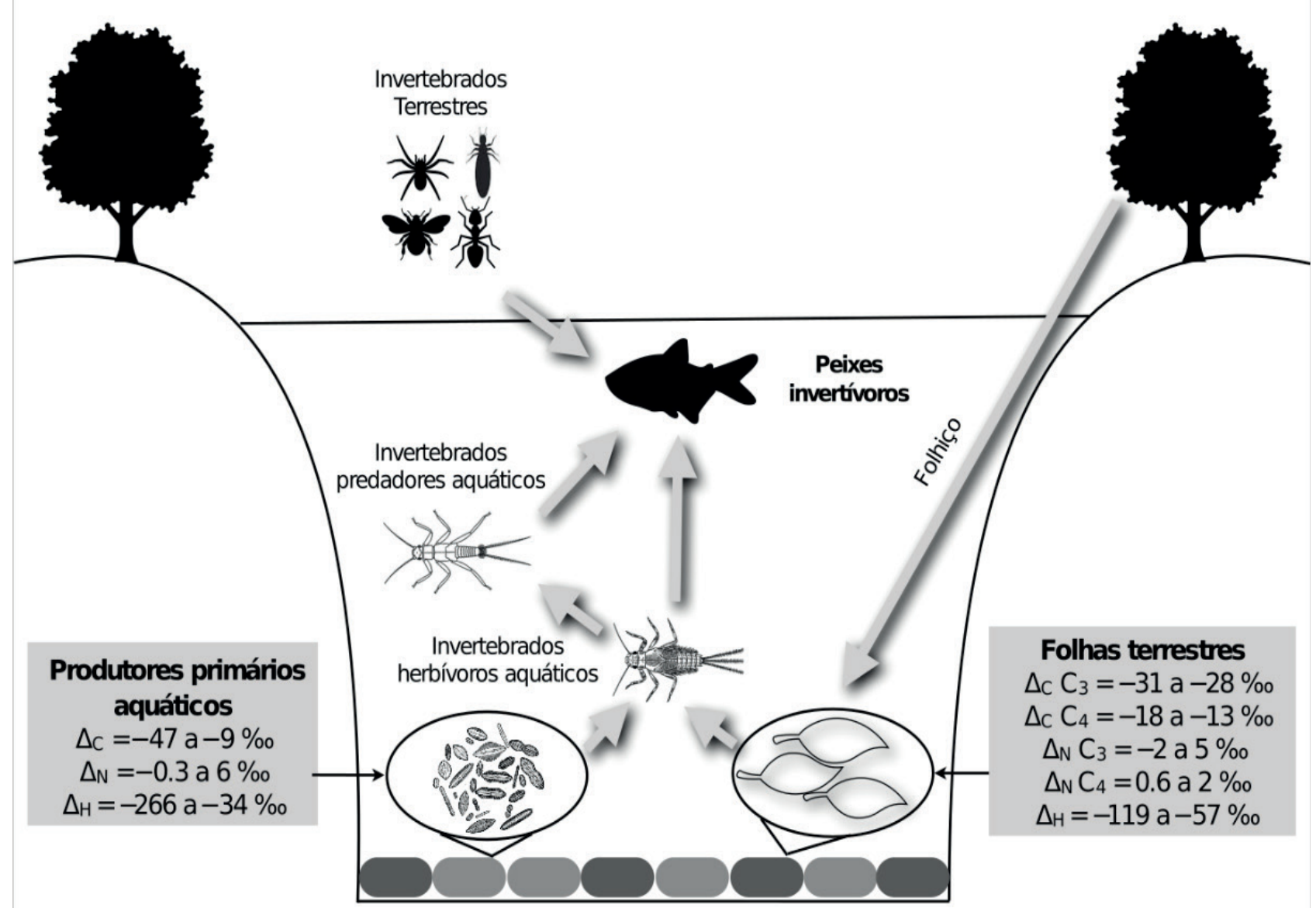

Figura 1. Perfil de um riacho, demonstrando as diferentes rotas da teia trófica, incluindo fontes basais autóctones e alóctones. As caixas nas laterais demonstram a variação $(\Delta)$ dos valores isotópicos de Carbono $(\mathrm{C})$, Nitrogênio $(\mathrm{N})$ e Hidrogênio $(\mathrm{H})$ de produtores primários aquáticos e terrestres.

Figure 1. Representation of a stream, showing the different linkages in the food web, including autochthonous and allochthonous basal sources. Side boxes show the variation $(\Delta)$ in the isotopic values of Carbon (C), Nitrogen $(N)$ and Hydrogen $(H)$ of aquatic and terrestrial primary producers.

Quadro 3. Terminologia e interpretação geral dos resultados.

Box 3. Terminology and general interpretation of results

A composição isotópica de um determinado composto (representada por delta, $\delta$ ) é calculada em relação a um padrão internacional, e expressa em partes por mil (\%):

$$
\delta \mathrm{X}(\%)=\left[\left(\mathrm{R}_{\text {amostra }} / \mathrm{R}_{\text {padrão }}\right)-1\right] \times 10^{3}
$$

, sendo $\mathrm{x}=$ isótopo estável $\left({ }^{13} \mathrm{C},{ }^{15} \mathrm{~N}\right)$ e $\mathrm{R}$ = razão entre o isótopo mais pesado e o mais leve $\left({ }^{13} \mathrm{C} /{ }^{12} \mathrm{C} ;{ }^{15} \mathrm{~N} /{ }^{14} \mathrm{~N}\right)$ (Fry 2006). Os padrões internacionais utilizados atualmente como referência são o Vienna PDB (VPDB) para o carbono e o nitrogênio atmosférico para o nitrogênio (Fry 2006). Os valores de $\delta$ calculados são medidas da quantidade do isótopo mais pesado em uma amostra. Assim, o termo "enriquecida" significa que uma amostra tem maior proporção de isótopos pesados em relação aos leves (maior $\delta x$ ) do que outra amostra (menor $\delta \mathrm{x}$ ), sendo esta última considerada "empobrecida" (depleted). 
recurso a ser assimilado e convertido em produção secundária. As plantas terrestres, apesar de sua alta disponibilidade em riachos, são repletas de lignina e celulose, o que as torna ricas em carbono (Elser et al. 2000, Brett et al. 2017) e altamente refratárias à digestão. As algas, ao contrário, muitas vezes limitadas em riachos pela baixa incidência de luz solar, possuem alta qualidade, sendo ricas em fósforo, nitrogênio e ácidos graxos ômega-3 poliinsaturados (Brett \& Müller-Navarra 1997, Guo et al. 2016).

Embora a importância de considerar a qualidade nutricional das algas venha sendo assinalada há bastante tempo, foi com base no uso de traçadores bioquímicos que as algas do perifíton têm se destacado como o principal recurso basal que sustenta teias tróficas em alguns riachos, com exemplos em ambientes temperados (Hayden et al. 2016) e tropicais (Brito et al. 2006, Reis et al. 2020, Hayden et al. 2021). Porém, alguns trabalhos sugerem que recursos alóctones são as fontes predominantes (Anjos 2013, em igarapés amazônicos), demonstrando que o debate sobre a importância relativa dessas fontes para a sustentação das teias tróficas de riachos permanece.

Os valores de $\delta^{13} \mathrm{C}$ de folhas C3 são geralmente $\sim-31$ a $-28 \%$ enquanto de folhas $\mathrm{C} 4,-18$ a $-13 \%$, e o perifíton pode ter uma maior amplitude de variação $(\sim-47 \%$ a $-9 \%$ ) devido a influência de fatores como produção primária, concentração de carbono inorgânico dissolvido, cobertura de dossel, área da bacia hidrográfica e fluxo de água (Ishikawa et al. 2012) (Figura 1). Dessa forma, se os valores dos recursos de origem alóctone e autóctone forem muito similares, não é possível diferenciar as fontes de $\mathrm{C}$ assimiladas pelos consumidores. A razão isotópica entre deutério $\left(\mathrm{H}^{2}\right)$ e prótio $\left(\mathrm{H}^{1}\right), \delta^{2} \mathrm{H}$ ou $\delta \mathrm{D}$, potencialmente distingue melhor as fontes dos recursos basais em riachos, pois a matéria orgânica alóctone é muito mais enriquecida em $\mathrm{H}^{2}$ do que a autóctone (Doucett et al 2007) (Figura 1). Os $\delta^{2} \mathrm{H}$ podem ser úteis para determinar as contribuições relativas de recursos alóctones e autóctones para os peixes. Em riachos de cabeceira tropicais (Tailândia), os valores de $\delta^{2} \mathrm{H}$ nas comunidades de peixes e invertebrados demonstraram maior assimilação de recursos autóctones (Hayden et al. 2021). Já em riachos de Trinidad, o peixe invertívoro Anablepsoides hartii (Cyprinodontiformes, Rivulidae) assimila principalmente recursos alóctones (Collins et al., 2016a), enquanto a onívora Poecilia reticulata (Cyprinodontiformes, Poeciliidae) tem menores $\delta^{2} \mathrm{H}$, indicando menor assimilação de recursos alóctones. Além disso, os $\delta^{2} \mathrm{H}$ mostram que o dossel influencia positivamente a quantidade de recursos alóctones assimilados por ambas as espécies (Collins et al. 2016a).

No entanto, o $\delta^{2} \mathrm{H}$ da vegetação terrestre nem sempre se distingue das plantas aquáticas vasculares (e.g. Hondula et al. 2014). Sendo assim, nos riachos em que este recurso é importante, a AIE de hidrogênio não é a mais recomendada. Para a aplicação da AIE de hidrogênio é necessário considerar a contribuição de $\mathrm{H}$ da água para o tecido do consumidor e, idealmente, determinar o $\delta^{2} \mathrm{H}$ da água do ambiente para corrigir o $\delta^{2} \mathrm{H}$ do consumidor (Apêndice 4). Em estudos experimentais, a contribuição da água do ambiente ( $\omega)$ para o $\delta^{2} \mathrm{H}$ do tecido muscular variou de $12 \%$ em Salvelinus fontinalis (Salmoniformes, Salmonidae) sem extração de lipídios (Solomon et al., 2009) a 23,1\% no músculo sem lipídios em tilápia-do-Nilo (Oreochromis niloticus - Cichliformes, Cichlidae) (Newsome et al. 2017), chegando a 33\% no músculo sem lipídios de Poecilia reticulata (Soto et al. 2013). Assim, o $\delta^{2} \mathrm{H}$ do tecido muscular de peixes possui uma proporção maior de $\mathrm{H}$ proveniente da dieta, que varia de acordo com a espécie e crescimento do peixe, e com o tamanho e o tipo de tecido da amostra analisada (Vander Zanden et al. 2016). Na ausência da medida específica do $\omega$ no próprio estudo para corrigir o $\delta^{2} \mathrm{H}$ do peixe, uma alternativa é assumir valores médios de $\omega \mathrm{e}$ suas variações (e.g. Wilkinson et al. 2015, Brett et al. 2018) e os mais apropriados para o peixe do estudo.

Uma vez que os controles biogeoquímicos de C, $\mathrm{N}$ e H são diferentes e suas respostas variam em cada ambiente, pode ser mais vantajoso usar vários rastreadores isotópicos em conjunto para resolver contribuições de fontes potenciais de nutrientes e seus caminhos na teia trófica aquática.

\section{Reconstrução da dieta}

A dieta de peixes de riacho tem sido 
tradicionalmente caracterizada por análises de conteúdo estomacal (ACE - ver Esteves et al. 2021), que fornecem informações sobre o que foi consumido recentemente pelo indivíduo. Já a composição isotópica de um consumidor é resultado de sua dieta em médio e longo prazo (Fry 2006); assim, a AIE em seus tecidos e nos de seus recursos alimentares permite a estimativa da contribuição relativa dos recursos assimilados, provendo uma descrição da dieta ao longo de semanas ou meses, dependendo da taxa de renovação do tecido analisado (Sacramento et al. 2016, Nielsen et al. 2018). Os valores de $\delta^{13} \mathrm{C}$ proveem informações sobre a fonte basal de carbono e os de $\delta^{15} \mathrm{~N}$ sobre a sua posição trófica (Fry 2006). Esses resultados são usualmente representados em gráficos de dispersão bidimensionais (biplots) (Figura 2). Para interpretar os valores isotópicos observados nos tecidos como informações sobre a composição da sua dieta, são utilizados modelos de mistura isotópica (Quadro 4 e Figura 3).

A reconstrução da dieta em Poecilia reticulata de riachos de Trinidad (Zandonà et al. 2017) e de Jenynsia multidentata (Cyprinodontiformes; Anablepidae) (Bastos et al. 2017) mostrou que, embora no conteúdo estomacal detritos e algas sejam predominantes, esses recursos tinham uma baixa assimilação. As AIE também são úteis para estudar a partilha de recursos. Em um riacho no sul do Brasil, a partilha de recursos foi apontada como um dos mecanismos de coexistência para espécies de lambaris (Characiformes, Characidae) morfologicamente similares: enquanto o herbívoro Astyanax xiru assimilou principalmente plantas aquáticas, Bryconamericus iheringii assimilou algas. Já os invertívoros Astyanax procerus e Bryconamericus sp. assimilaram principalmente insetos terrestres e insetos aquáticos, respectivamente (Bonato et al. 2018).

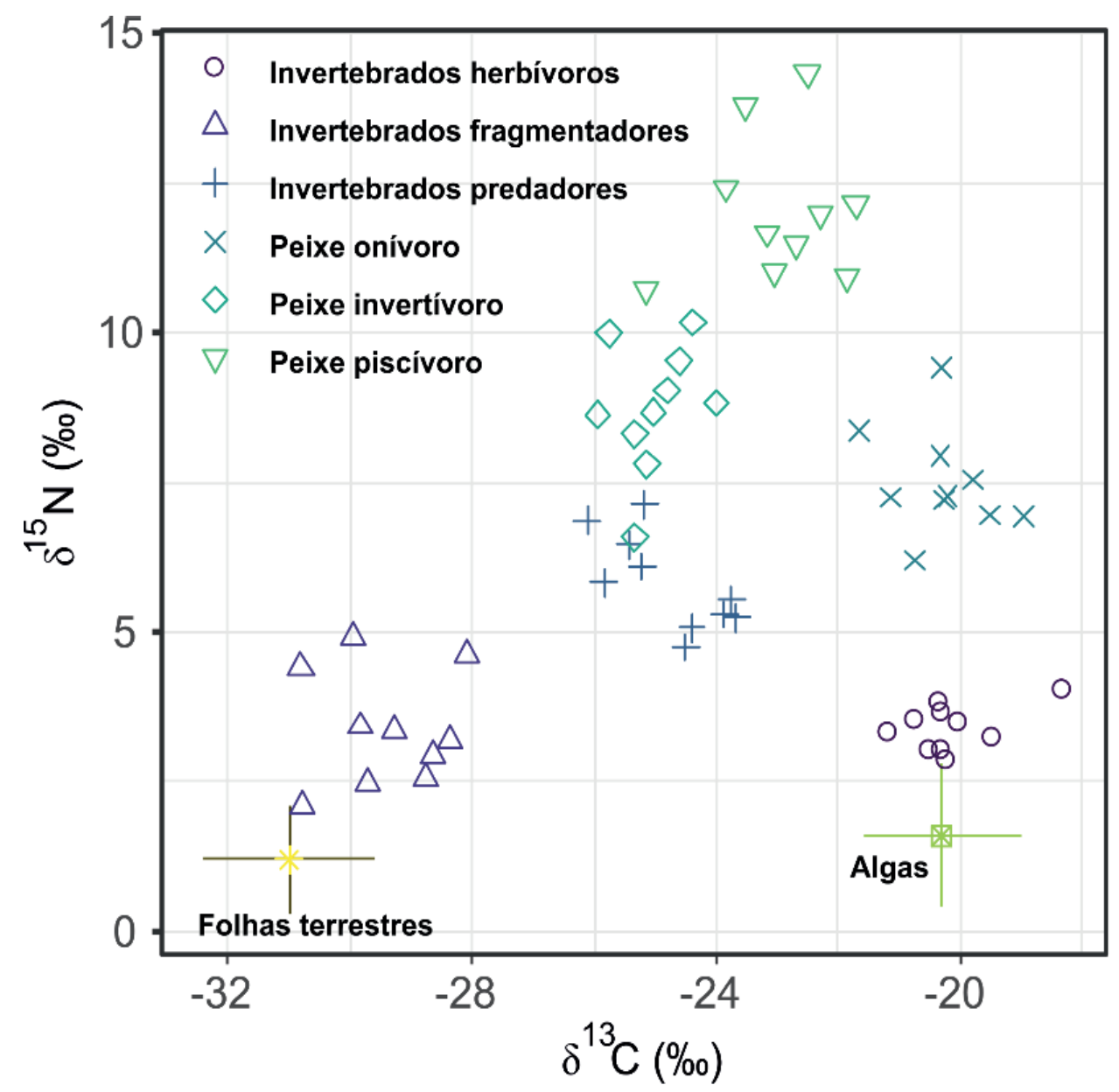

Figura 2. Valores hipotéticos de $\delta^{13} \mathrm{C}$ e $\delta^{15} \mathrm{~N}$ de recursos alimentares basais, de invertebrados e peixes de diferentes guildas tróficas.

Figure 2. Hypothetical $\delta^{13} C$ e $\delta^{15} N$ values for basal resources, and trophic guild of invertebrates and fish from different trophic guilds. 


\section{Posição trófica}

A definição da posição trófica (PT) de organismos que habitam os riachos é um dos primeiros passos para entender seu papel e a ecologia destes sistemas. Assim como a dieta, a posição trófica dos peixes tem sido tradicionalmente estimada com base em ACE, mas pode também ser calculada através dos isótopos, especialmente de nitrogênio, provendo informações adicionais sobre a aquisição e transferência de energia entre recursos e consumidores. Como os valores isotópicos dos recursos basais variam temporalmente e espacialmente, para poder comparar as posições tróficas de organismos de diferentes ecossistemas e localidades é necessário definir uma baseline (valor basal) isotópica que precisa ser incorporada no cálculo de PT (Post 2002). Invertebrados herbívoros raspadores e detritívoros são frequentemente utilizados como baselines isotópicas, representando, respectivamente, os recursos basais autóctones e alóctones (Zandonà et al. 2017). A equação mais utilizada para o cálculo de PT é a de Post (2002), que utiliza modelos de mistura com duas baselines de origem diferente:

$\mathrm{PT}=\lambda+\left(\delta^{15} \mathrm{~N}_{\text {peixe }}-\left[\delta^{15} \mathrm{~N}_{\text {baselinel }} \mathrm{x} \alpha+\delta^{15} \mathrm{~N}_{\text {baseline2 }} \mathrm{x}(1-\alpha)\right] / \Delta\right.$

, onde $\lambda$ é a PT dos organismos usados como baseline (e.g. 1 se forem invertebrados herbívoros ou detritívoros), $\alpha=$ proporção de $\mathrm{N}$ no peixe que se origina do recurso basal 1 (e.g. algas $v$ s. folhas), $\mathrm{e}$ $\Delta=$ fator de enriquecimento trófico. Para calcular $\mathrm{o} \alpha$, pode-se utilizar um modelo de mistura misto com dois recursos basais de valores extremos (end members) dessa forma (Post 2002):

$$
\alpha=\left(\delta^{13} C_{\text {peixe }}-\delta^{13} C_{\text {baseline2 }}\right) /\left(\delta^{13} C_{\text {baseline1 }}-\delta^{13} C_{\text {baseline2 }}\right)
$$

A determinação acurada do $\Delta$ (Quadro 4) é uma das principais dificuldades nos cálculos de PT, pois é afetado por diversos fatores, inclusive a dieta, o que se torna problemático especialmente para organismos onívoros (Vanderklift \& Ponsard 2003). Para contornar esse problema, é possível utilizar um valor de $\Delta$ específico para cada recurso alimentar consumido e ponderálo em proporção à sua assimilação de acordo com estimativas do modelo de mistura (Bastos et al. 2017). Essa abordagem permitiu calcular
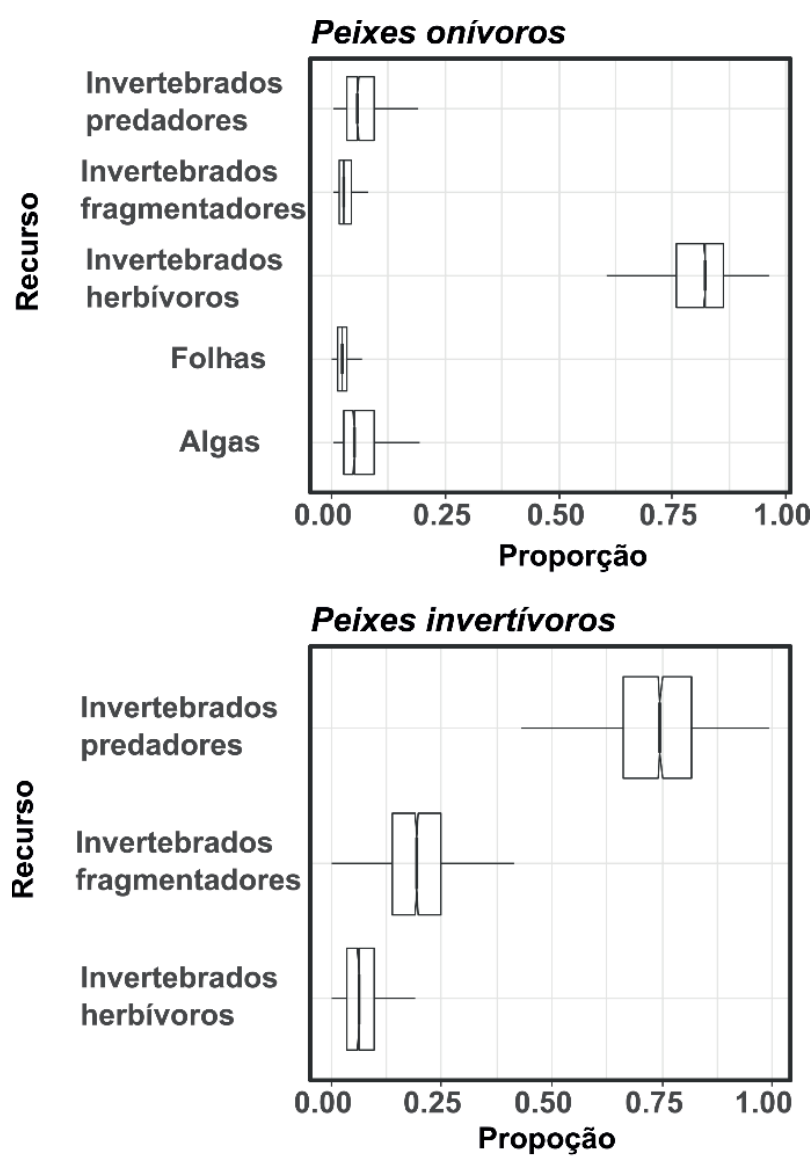

Peixes piscívoros

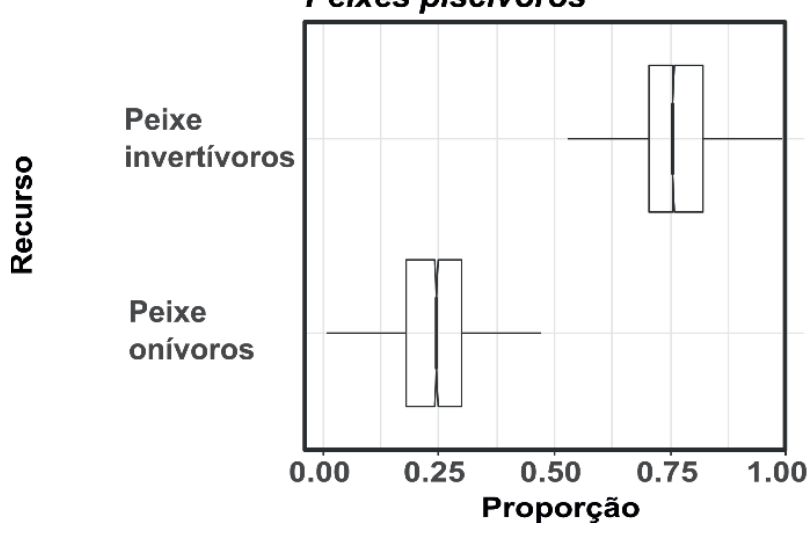

Figura 3. Contribuição proporcional dos recursos alimentares assimilados pelas guildas de peixes. Modelo de mistura baseado nos valores de $\delta^{13} \mathrm{C} \mathrm{e}$ $\delta^{15} \mathrm{~N}$ hipotéticos apresentados na Figura 2.

Figure 3. Proportion of food resources assimilated by fish guilds. The mixing model is based on hypothetical $\delta^{13} \mathrm{Ce} \delta^{15} \mathrm{~N}$ values shown in Figure 2.

com mais precisão a PT de múltiplas populações de Jenynsia multidentata que se alimentam de recursos de origem animal e vegetal em proporções diferentes (Bastos et al. 2017).

$O$ fato de que nem todos os itens ingeridos pelos animais são assimilados na mesma proporção em que são consumidos tem implicações sobre o papel trófico das espécies. Em riachos de 
Quadro 4. Modelos de mistura e Fator de Enriquecimento Trófico.

Box 4. Mixture models and Trophic Enrichment Factor

As estimativas do modelo de mistura da contribuição de diferentes fontes de alimentos são necessárias na maioria dos estudos que empregam análises de isótopos estáveis. Os modelos de mistura baseiam-se em equações de balanço de massa e nos valores isotópicos distintos de várias fontes alimentares para determinar suas contribuições relativas ao valor de isótopos de um consumidor. Por exemplo, o valor isotópico de um consumidor $\left(\delta \mathrm{X}_{\text {cons }}\right)$ pode ser definido com um modelo básico de mistura de balanço de massa (Moore \& Semmens 2008) da seguinte forma:

$$
\delta X_{\text {cons }}=f_{1} *\left(\delta X_{1}+\Delta \delta X_{1}\right)+f_{2} *\left(\delta X_{2}+\Delta \delta X_{2}\right)+\ldots+f_{n} *\left(\delta X_{n}+\Delta \delta X_{n}\right)
$$

onde $\mathrm{f}_{\mathrm{i}}$ representa a contribuição proporcional da fonte i para os consumidores e $\mathrm{o} ; \delta \mathrm{X}_{\mathrm{i}}$ representa a assinatura isotópica da i-ésima fonte, e $\Delta \delta \mathrm{X}_{\mathrm{i}}$ é o fator de enriquecimento trófico (FET) específico do isótopo da i-ésima fonte. $\mathrm{O}$ fator de enriquecimento trófico pode ser definido como a mudança isotópica entre a dieta e o consumidor. $\mathrm{O}$ enriquecimento de ${ }^{13} \mathrm{C}$ em organismos heterotróficos se dá porque os processos fisiológicos, como respiração, liberam ${ }^{12} \mathrm{CO}_{2}$ mais rapidamente que o ${ }^{13} \mathrm{CO}_{2}$, o que resulta em um FET médio de $\delta^{13} \mathrm{C}$ de c. $+0.4 \%$ o $\left(\mathrm{SD}=1 \%\right.$ ). Já o FET médio de $\delta^{15} \mathrm{~N}$ do consumidor é c. $+3.4 \%$ ( $\mathrm{SD}=1$ \%) devido ao enriquecimento de ${ }^{15} \mathrm{~N}$ dos organismos heterotróficos em relação a sua dieta em função do fato de que a excreção de ${ }^{14} \mathrm{~N}$-uréia e e ${ }^{14} \mathrm{~N}$-amônia ocorre em uma taxa mais rápida do que ${ }^{15} \mathrm{~N}$-uréia e ${ }^{15} \mathrm{~N}$-amônia (Fry 2006; Vander Zanden \& Rasmussen 1999). Ainda há dúvidas sobre se há mudança relevante na razão deutério:prótio $\left({ }^{2} \mathrm{H}:{ }^{1} \mathrm{H}\right)$ entre dieta e consumidor e alguns autores assumem que essa mudança é pequena em relação à variação de $\delta^{2} \mathrm{H}$ no ambiente. Contudo, dependendo dos objetivos, faz-se necessário corrigir o $\delta^{2} \mathrm{H}$ do consumidor devido a contribuição de da água ambiental ( $\left.\omega\right)$. Há um aumento progressivo do valor de $\omega$ em cada nível trófico $(\tau)$ que pode ser estimado de acordo com a equação (Solomon et al. 2009):

$$
\omega_{\text {consumidor }}=1-\left(1-\omega_{\text {médio }}\right)^{\tau}
$$

E o $\delta^{2} \mathrm{H}$ corrigido pode ser estimado usando a equação (Dekar et al. 2012):

$$
\delta^{2} \mathrm{H}_{\text {corrigido }}=\left[\delta^{2} \mathrm{H}_{\text {consumidor }}-\left(\delta^{2} \mathrm{H}_{\text {corrigido }} * \omega_{\text {consumidor }}\right)\right] /\left(1-\omega_{\text {consumidor }}\right)
$$

Tendo em vista as incertezas no valor da contribuição de água no $\delta^{2} \mathrm{H}$ do consumidor, recomenda-se uma avaliação da estabilidade dos resultados frente a essa variação como um teste de sensibilidade.

Modelos baseados em sistemas em que o número de equações é igual ao número de incógnitas são determinados, enquanto modelos onde o número de equações é menor que o número de incógnitas são subdeterminados. Dessa forma, modelos de mistura que tem um número de fontes maior do que o número de tipos isotópicos +1 são subdeterminados e isso implica que todas as soluções de $\mathrm{f}_{\mathrm{i}}$ são viáveis e que as contribuições da fonte mais comumente usada são subestimadas, enquanto as contribuições das fontes menos usadas são superestimadas (Boecklen 2011). Devido a essas implicações, recomenda-se relatar a variação de contribuição percentual de cada fonte como os intervalos de credibilidade, em vez de relatar apenas as estimativas pontuais como as médias. Ressalta-se que, todo resto sendo igual, quanto maior o número de fontes comparado ao número de tipos isotópicos, maior será a variação de contribuições de cada fonte.

Os modelos de mistura mais recentes, como o MixSir (Moore \& Semmens 2008), siar (Parnell et al. 2010), MixSIAR (Stock \& Semmens 2016) e simmr (Parnell 2020), incorporam uma variedade de fontes de incerteza, como medidas de variação dos valores isotópicos dos consumidores, recursos, fator de enriquecimento trófico e a concentração de C e N dos recursos. Portanto, o uso de razões de isótopos estáveis para traçar caminhos de matéria orgânica entre os consumidores requer estimativas acuradas da mudança isotópica entre a dieta e os consumidores, porque erros nas estimativas de mudança do fator de enriquecimento trófico podem resultar em erros nas estimativas da contribuição das fontes para consumidores (McCutchan et al. 2003). As estimativas da FET, geralmente, baseiam-se em experimentos controlados de alimentação e a FET pode variar em função do tipo de dieta, tecido analisado e de preparação das amostras, conteúdo de proteína do recurso alimentar etc. (Post et al.2002, McCutchan et al. 2003, Vanderklift \& Ponsard 2003, Sacramento et al.2016). A premissa básica para utilizar os modelos de mistura é que os valores isotópicos estejam dentro do polígono dos valores isotópicos dos recursos alimentares acrescidos do FET. Os resultados dos modelos de misturas retornam as estimativas de valores de contribuição proporcional dos recursos alimentares assimilados pelos consumidores que atendem a equação de balanço de massas (Figura 3). 
Mata Atlântica, foi observada correlação entre as posições tróficas calculadas com base em ACE e AIE para peixes insetívoros e algívoroinsetívoros, ao contrário dos onívoros e algívorodetritívoros (Reis et al. 2020). A não correlação demonstra que os peixes dessas guildas estão provavelmente assimilando fontes nutricionais pouco representadas no conteúdo estomacal, e, ao mesmo tempo, desempenhando um papel trófico diferente do indicado pelos recursos consumidos, ou seja, o consumo não reflete o fluxo de energia na teia (Reis et al. 2020). Este e outros exemplos (e.g. Zandonà et al. 2017, Bonato et al. 2018, Carvalho et al. 2019) demonstram que é recomendável o uso combinado de ACE e AIE.

Os isótopos de hidrogênio podem servir também como indicadores da posição trófica dos consumidores, complementando as informações do $\delta^{15} \mathrm{~N}$. A cada nível trófico, o consumidor adiciona uma fração de $\mathrm{H}$ de sua água corporal durante a biossíntese de seus tecidos, e, dentro das teias aquáticas autóctones, este $\mathrm{H}$ é enriquecido em relação ao recurso basal (Vander Zanden et al. 2016). Assim, ao consumir invertebrados e/ou outros peixes, que já incorporaram um $\mathrm{H}$ adicional isotopicamente pesado de sua água corporal em seus tecidos, um peixe terá aumento de $\delta^{2} \mathrm{H}$ ao produzir seus novos tecidos (ver revisão de Vander Zanden et al. 2016).

\section{Nicho isotópico e métricas de estrutura trófica de comunidades}

Análises de isótopos têm sido utilizadas para representar o nicho isotópico de populações e comunidades (Shipley \& Matich 2020). A maior parte das definições de nicho retém a ideia de espaço n-dimensional, com eixos relacionados ao habitat, ou seja, às condições ambientais (scenopoetic) e eixos relacionados ao uso de recursos (bionomic) (Hutchinson 1978). Recentemente, o nicho tem recebido atenção renovada, e, com o desenvolvimento da ecologia isotópica, partindo da ideia de que a composição química dos animais é diretamente influenciada pelo que consomem e pelo habitat onde vivem, o nicho pode ser representado em um "espaço isotópico" (por exemplo, $\delta^{13} \mathrm{C} v s . \delta^{15} \mathrm{~N}$ ou $\delta^{2} \mathrm{H}$ ), comparável ao espaço n-dimensional do nicho (Newsome et al. 2007).

Estendendo esses conceitos, Layman et al. (2007a) propuseram métricas para descrever de forma integrada a estrutura trófica em nível populacional ou da comunidade. Nessas métricas, o nicho isotópico dos consumidores pode ser medido em um espaço bidimensional, onde a área ocupada pela amplitude de valores de $\delta^{13} \mathrm{C}$ representa a diversidade de fontes de carbono assimiladas e a de $\delta^{15} \mathrm{~N}$, a amplitude de posições tróficas. Em conjunto, formam a área total (AT), que é a área convexa mínima no espaço bidimensional isotópico contendo osindivíduos de uma população ou comunidade. A AT representa o nicho realizado e, desta forma, é um indicador para a diversidade trófica (Figura 4). Já a distância média para o centróide (DC) mede o grau médio de diversidade trófica na teia. As demais métricas se relacionam com as distâncias entre os membros da comunidade ou população, representando seu espaçamento na formação da AT e permitindo, assim, inferir sobre a redundância ou divergência de nicho trófico. Por exemplo, menores valores da média das distâncias dos vizinhos mais próximos (DVP) para cada espécie ou indivíduo sugerem uma distribuição mais uniforme dos nichos tróficos, ou seja, maior redundância trófica. O desvio padrão das DVP permite as mesmas medidas, mas com menos influência do tamanho da amostra.

Essas métricas receberam algumas críticas (Zeug \& Hoeinghaus 2008), especialmente por serem sensíveis ao tamanho amostral e por não considerarem possíveis variações nos recursos basais dentrodoprópriosistema, sendo, assim, não comparáveis entre sistemas. A variação isotópica intra- e interpopulacional depende não somente da variabilidade das dietas, mas também da variação isotópica entre as fontes basais. Jackson et al. (2011) propuseram aperfeiçoamentos nessas métricas ao incorporarem técnicas de inferência Bayesiana, que incluem fatores de incerteza e variabilidade nos seus parâmetros de entrada. Essas métricas foram denominadas SIBER (Stable Isotope Bayesian Ellipses in R), e seu uso vem se tornando crescente em estudos ecológicos. A área padrão da elipse (Standard Ellipse Area-SEA) representa o centro espacial do nicho isotópico (Figura 4), sendo um substituto (proxy) para a riqueza e equabilidade de recursos consumidos pela população (Bearhop et al. 2004) ou comunidade (Carvalho et al. 2017).

Embora alguns autores apontem que os 
termos 'nicho trófico' e 'nicho isotópico' nem sempre podem ser intercambiáveis (ver revisão de Shipley \& Matich 2020), essas métricas podem ser utilizadas, por exemplo, para identificar a amplitude de nicho trófico de uma população (Carvalho et al. 2019) ou comunidade (Carvalho et al. 2017), sobreposição de nicho (Shipley \& Matich 2020), mudanças em resposta a alterações ambientais relacionadas ao uso do solo (Carvalho et al. 2017) ou outras relevantes à conservação, como a introdução de espécies não nativas (Carvalho et al. 2019).

Comunidades de peixes de riachos de Cerrado sob influência de plantações de cana-de-açúcar apresentaram menor amplitude de nicho isotópico (menor $S E A$ ), apesar da grande variação de $\delta^{13} \mathrm{C}$ dos recursos, além de menor diversidade e alta redundância, tanto trófica quanto na composição (Carvalho et al. 2017). Nos riachos de pastagem, ao contrário, as comunidades tiveram a maior diversidade trófica, com os peixes acompanhando a maior amplitude de $\delta^{13} \mathrm{C}$ dos recursos basais e macroinvertebrados, sugerindo que foram capazes de utilizar essa maior gama de recursos (Carvalho et al. 2017). O uso do solo pode, então, alterar a composição isotópica de consumidores e recursos, e nem sempre a comunidade de peixes reflete a total amplitude de valores de $\delta^{13} \mathrm{C}$ dos níveis mais basais, seja pela ausência de determinadas espécies ou por parte desses recursos não ser assimilável.

\section{Impactos antrópicos}

Os riachos e suas zonas ripárias formam ecossistemas interligados por subsídios energéticos. Além de promover o influxo de recursos alóctones, a mata ripária influencia diretamente a regulação da produção primária, pelo efeito do sombreamento, além de ter papel na estruturação física do riacho, ao conter processos erosivos e promover a heterogeneidade de microhabitat. Mudanças do uso do solo podem impactar a qualidade da água e a estrutura trófica da ictiofauna de riachos.

A AIE constitui uma ferramenta útil a ser usada para detectar impactos decorrentes de ações antrópicas, como alterações na qualidade da água (e.g. Carvalho et al. 2020) e no uso do solo devido à urbanização ou desmatamento com substituição por pastagens ou agricultura (e.g. Carvalho et al.

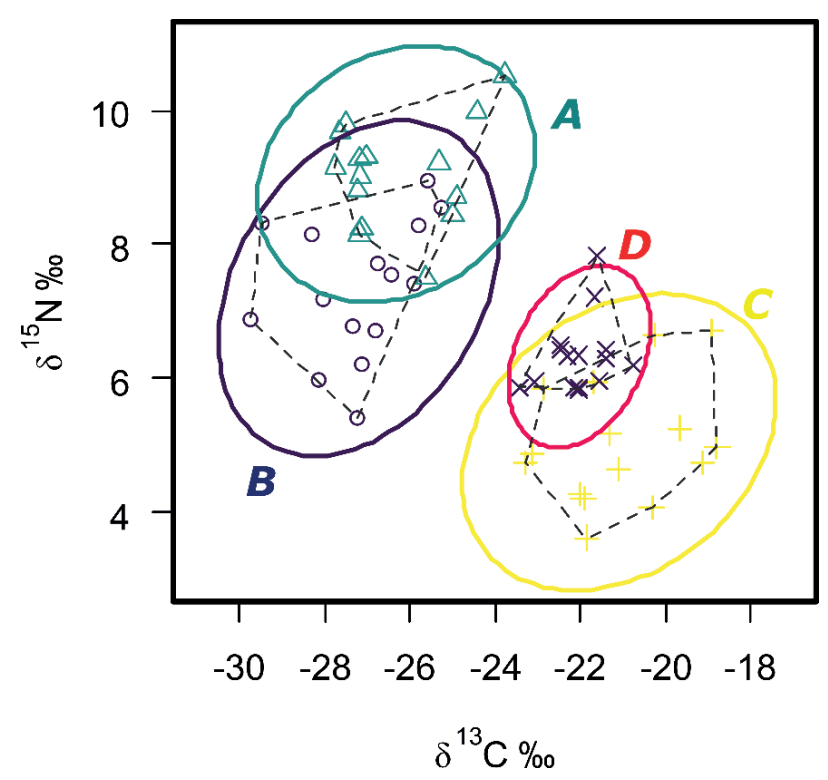

Figura 4. Representação hipotética no espaço isotópico bidimensional de indivíduos de quatro comunidades ou populações de peixes. As linhas pontilhadas demonstram a Área Total (Layman et al. 2007a) e as linhas cheias, a Área Padrão da Elipse (SEA - Jackson et al. 2011). A comunidade/ população D apresenta a menor diversidade trófica e há sobreposição parcial de nicho isotópico entre $\mathrm{A}$ e B, e C e D.

Figure 4. Hypothetical distribution in twodimensional isotopic space of individuals from four communities or populations of fish. The dotted lines show the Total Area (Layman et al. 2007a) and the solid lines, the Standard Ellipse Area (SEA - Jackson et al. 2011). Community/population D has the least trophic diversity, and there is partial overlap of isotopic niche between $A$ and $B$, and $C$ and $D$.

2017). A adição de nutrientes através do esgoto doméstico ou dejetos da pecuária, associados com a maior incidência de luz pelo desmatamento da zona ripária podem aumentar a biomassa do perifíton (Bunn et al. 1999) e modificar os valores isotópicos deste recurso basal (Carvalho et al. 2020). Por exemplo, no Cerrado, a contribuição de perifíton e algas para o peixe não nativo Knodus moenkhausii (Characiformes; Characidae) foi o dobro nos riachos com vegetação ripária substituída por pastagens do que aquela nos riachos preservados (Carvalho et al. 2019). Nesse mesmo conjunto de riachos, outros peixes apresentaram $\delta^{15} \mathrm{~N}$ mais enriquecidos nos riachos com pastagem e cana-de-açúcar do que nos preservados (Carvalho et al. 2015). Alterações nos valores isotópicos dos peixes frente a diversos distúrbios ou variações ambientais podem ser 
decorrentes da adição de novos recursos na dieta ou de mudanças nas razões isotópicas dos recursos já consumidos. Neste mesmo estudo, apenas Astyanax altiparanae (Characiformes, Characidae) teve alterações isotópicas em função da incorporação de novos itens na dieta (Carvalho et al. 2015).

Assim, a AIE dos peixes e seus recursos apresenta-se como ferramenta para identificar as mudanças e a intensidade dos impactos antrópicos localmente e regionalmente na bacia hidrográfica do riacho. Com o advento e popularização de tecnologias de sistema de informação geográfica (SIG) é possível incorporar escalas mais amplas e testar suas influências sobre padrões e processos ecológicos, incluindo as interações tróficas da ictiofauna (e.g. Reis et al. 2020). Isso se torna especialmente relevante em ecossistemas lóticos, onde o fluxo direcional da água carrega diversas alterações, tanto na qualidade da água quanto no uso do solo, de montante para jusante.

\section{Novas fronteiras}

Além das análises de isótopos estáveis em tecidos, existe uma gama de ferramentas mais recentes ou ainda pouco utilizadas com peixes de riachos, especialmente no Brasil, que incluem abordagens mais experimentais ou abordam questões relacionadas à qualidade nutricional, assimilação de recursos e distinção de sua origem, entre outras. A seguir, reportamos algumas das ferramentas mais interessantes e com maior potencial para serem implementadas em estudos tróficos de peixes de riachos tropicais.

\section{Adição de Traçadores Isotópicos para medidas de Fluxos de Energia e de Nutrientes}

Os valores de abundâncias naturais de isótopos dos organismos podem ser utilizados para traçar os fluxos de $\mathrm{C}$ nas teias tróficas (Neres-Lima et al. 2017). Mas experimentos com adição de soluções de isótopos enriquecidos permitem reconstruir fluxos de nutrientes e de energia nas teias tróficas, monitorando sua absorção e transformação ao longo do tempo nos vários compartimentos tróficos (Collins et al. 2016b). Por exemplo, adição de soluções enriquecidas de ${ }^{13} \mathrm{C}$ e de ${ }^{15} \mathrm{~N}$ são utilizadas para melhor entender a contribuição de fontes de $\mathrm{C}$ de origem alóctone ou autóctone na teia trófica, já que frequentemente essas fontes não têm valores isotópicos naturais distinguíveis (Hotchkiss \& Hall 2015). C e N inorgânicos dissolvidos são absorvidos pelas algas; assim, adicionando soluções desses nutrientes com isótopos enriquecidos, é possível traçar a contribuição das algas como fonte de energia ao longo da teia trófica (Collins et al. 2016b, c). $\mathrm{O}^{15} \mathrm{~N}$-amônio é utilizado por produtores primários e bactérias (Collins et al. 2016b). O perifíton é formado por uma mistura de algas, detrito, fungos e bactérias, mas é difícil separar esses componentes para entender o quanto os organismos heterotróficos e autotróficos do perifíton, respectivamente, alimentam as teias tróficas (Collins et al. 2016b). O acetato é um composto de carbono orgânico dissolvido que é rapidamente assimilado pelas bactérias, mas não é usado por produtores primários. Assim, adição de acetato enriquecido de ${ }^{13} \mathrm{C}$ pode ser utilizada para quantificar o fluxo de energia bacteriana nas teias tróficas (Collins et al. 2016b). O bicarbonato é usado como um substrato primário para a fotossíntese por produtores primários, mas não por bactérias, e, portanto, a adição de bicarbonato enriquecido de ${ }^{13} \mathrm{C}$ pode ser utilizado para isolar e identificar o fluxo de energia proveniente dos produtores primários ao longo da teia trófica (Hotchkiss \& Hall 2015). Experimentos desse tipo, que nos trópicos ainda são escassos, mostraram que o fluxo de $\mathrm{C}$ de origem bacteriana que alimenta a teia trófica, até os peixes, pode ser proeminente especialmente em riachos com elevada cobertura de dossel (Collins et al. 2016b).

\section{Análise de Isótopos Estáveis em Compostos Específicos}

AIE em compostos específicos (AIECE) determina os valores isotópicos em compostos orgânicos individuais, como aminoácidos (Whiteman et al. 2019) e ácidos graxos (Fujibayashi et al. 2019). Essa ferramenta potencialmente oferece soluções para algumas das limitações da AIE, como quando os modelos de mistura não são capazes de discriminar os recursos utilizados pelo consumidor (Stock et al. 2018). Mesmo que os tecidos dos recursos apresentem valores isotópicos similares em certos contextos, as moléculas que compõem esses tecidos podem ter valores isotópicos distintos, diferenciandoos entre si (Twining et al. 2020). Por exemplo, em 
uma relação entre IE de $\delta^{13} \mathrm{C}$ em ácidos graxos do epilíton e do folhiço com os de Salvelinus leucomaeni (Salmoniformes, Salmonidae), pôdeseentender quea origem doácidograxo DHA (ácido docosahexaenóico, 22:6ஸ3) desta espécie em riachos temperados no Japão, veio diretamente e/ou derivou da molécula precursora (EPA - ácido eicosapentaenóico, 20:5 $\omega 3$ ) do epilíton, apesar de esta molécula também estar presente no folhiço destes riachos (Fujibayashi et al. 2019). Portanto, é possível utilizar a diferenciação da abundância natural dos isótopos estáveis dos recursos em uma escala fina para rastrear o movimento e a transferência desses compostos específicos na teia trófica.

\section{Análise de Ácidos Graxos}

A análise de ácidos graxos (AAG), especialmente os poliinsaturados (PUFA), indica a qualidade nutricional dos recursos aos consumidores. Em ambientes lóticos, a composição de PUFA nos organismos é bem documentada, porém o conhecimento sobre sua transferência ao longo da cadeia ainda é limitado (Guo et al. 2017). Existe uma grande diferença na composição de PUFAs entre recursos basais alóctones e autóctones (Guo et al. 2017). As algas de riachos subtropicais e temperados, especialmente as diatomáceas, são recursos de alta qualidade para os consumidores em comparação às folhas frescas e os detritos, pois contêm uma maior porcentagem de ácidos graxos essenciais, como o EPA (Lau et al. 2009). Esta porcentagem é influenciada pela entrada de nutrientes e luz no riacho (e.g. Cashman et al. 2013), e alterações do uso do solo (e.g. Boëchat et al. 2011). Já as plantas terrestres possuem alta porcentagem de ALA (ácido alfa-linolênico,

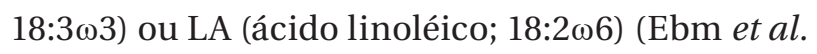
2020). Baseado nisto, é possível calcular a razão $\omega-3 / \omega-6$ (ômega-3/ ômega-6) da composição de PUFAs dos organismos para identificar a fonte primária de matéria orgânica. Por exemplo, em invertebrados de riachos, a razão $\omega-3 / \omega-6>1$ indica que algas são mais importantes do que material terrestre, independentemente do seu modo de alimentação. Em peixes de riacho, ao contrário, a composição dos PUFAs não necessariamente reflete a mesma diversidade de seus recursos alimentares (Fujibayashi et al. 2019). Os peixes dulcícolas apresentam altas porcentagens de LA

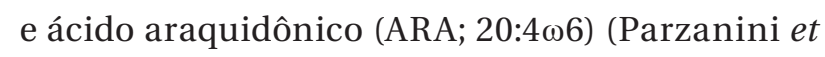
al. 2020). Dentre os PUFAs de longas cadeias (LCPUFA), os peixes, seletivamente, retêm o DHA em seus tecidos, pois este composto é importante para o desenvolvimento neural e acuidade visual (Guo et al. 2017). Porém, o nível de retenção deste composto em cada espécie vai depender de sua dieta e de sua habilidade de biossintetizar o DHA. Com base em estudos em riachos temperados e subtropicais, supõe-se que os peixes derivam seu DHA convertendo a molécula precursora EPA das algas e/ou via macroinvertebrados (e.g. Ebm et al. 2020). Até o momento não há estudos em peixes de riachos tropicais, apenas com peixes de um reservatório tropical (Gomes et al. 2016), sendo uma abordagem promissora como uma alternativa ou complemento à AIE em tecidos.

\section{Estequiometria - Limiar de Proporções de Elementos (Threshold Elemental Ratio - TER)}

A Estequimetria Ecológica estuda as interações ecológicas através do balanço de massa e de energia, considerando os organismos como um conjunto de elementos químicos (ver Zandonà et al. 2021). Com a ideia que existe um desequilíbrio entre organismos e as suas dietas, e que os animais são homeostáticos (i.e., as suas composições de elementos são relativamente estáticas), foi introduzido o conceito de Limiar de Proporções de Elementos (Frost et al. 2006). Esse conceito é utilizado para entender a demanda e limitação de nutrientes nos animais, pois prediz qual seria a razão de elementos da dieta onde a limitação para o crescimento muda de um elemento para outro (geralmente C: nutriente). Por exemplo, esta ferramenta foi utilizada para entender o desbalanço entre demanda de nutrientes e dieta de populações de Poecilia reticulata, mostrando que as populações com uma dieta mais rica em detrito e mais pobre em invertebrados, teriam um desbalanço C:P mais negativo, indicando uma limitação por P (El-Sabaawi et al. 2012).

\section{Geometria nutricional}

A geometria nutricional (GN - Raubenheimer \& Simpson 1993) é um arcabouço quantitativo para estudar a ecologia nutricional dos organismos. Origina-se da ecologia de comportamento e estratégias de forrageamento, e se propõe a entender como a disponibilidade 
de determinados nutrientes que compõem a dieta de um organismo influencia a seleção de recursos alimentares, a fisiologia e a aptidão das espécies (Simpson \& Raubenheimer 2012). A GN foca nos macronutrientes, como proteínas, carboidratos e ácidos graxos, micronutrientes, como vitaminas e minerais e outros componentes não nutricionais, como fibras e aleloquímicos (Simpson \& Raubenheimer 2012).

\section{CONCLUSÕES}

A utilização das análises de isótopos estáveis (AIE) tem representado um grande avanço na compreensão do fluxo energético da teia trófica, do papel e interações tróficas entre as espécies e das respostas da ictiofauna sob influência das variações naturais e antrópicas em riachos. Os estudos utilizando esta ferramenta para peixes de riacho no Brasil ainda são incipientes e têm se dedicado majoritariamente a identificar as principais fontes de carbono e alterações na dieta de espécies ou estrutura trófica de comunidades em resposta a impactos.

Estudos em Mata Atlântica e Cerrado, em diferentes graus de conservação, têm revelado maior predominância de fontes autóctones na sustentação de consumidores. Consumidores de alguns igarapés amazônicos apresentaram fortes marcas da vegetação terrestre, sugerindo que a alta disponibilidade deste recurso também está sendo assimilada pelos peixes e macroinvertebrados nesses sistemas (Anjos 2013). No entanto, são necessários estudos para confirmar se este é, de fato, um padrão em igarapés e quais seriam os fatores determinantes para esse padrão. Da mesma forma, se as fontes primárias de carbono predominantes para os peixes em riachos estão relacionadas com o tipo de bioma, permanece uma questão a ser investigada, já que diversos biomas brasileiros ainda não foram estudados sob este aspecto.

Apesar dos avanços propiciados pela AIE, a interpretação dos dados frequentemente encara ainda incertezas e limitações, como a grande variação e por vezes sobreposição de $\delta^{13} \mathrm{C}$ dos produtores primários (Brett et al. 2017), dificuldades de determinar o fator de enriquecimento trófico (Apêndice 4) e as taxas de renovação (turnover) dos tecidos (Sacramento et al. 2016). Revisões salientam que o progresso na AIE resultará de mais estudos experimentais (Martinez del Rio et al. 2009), especialmente para calibração de parâmetros de modelos (Boecklen et al. 2011), da padronização de métodos e modelos (Layman et al. 2012) e do desenvolvimento de abordagens mais recentes como AIE de compostos específicos (Boecklen et al. 2011, Nielsen et al. 2018).

Algumas das ferramentas mencionadas na seção "Novas fronteiras", constituem desdobramentos da AIE que pretendem resolver algumas dessas incertezas e limitações. Outras abordagens ainda mais recentes e incipientes podem ser mencionadas, como o uso de isótopos de oxigênio em tecidos como um marcador adicional (Vander Zanden et al. 2016, Nielsen et al. 2018) ou radiocarbono em associação com isótopos estáveis em modelos de mistura (Ishikawa et al. 2020).

A abordagem metodológica mais adequada para cada estudo vai depender da pergunta a ser respondida. Ao mesmo tempo, essas novas ferramentas representam grandes desafios na realidade dos estudos ecológicos brasileiros, uma vez que demandam mais recursos financeiros e procedimentos laboratoriais mais elaborados às vezes não disponíveis no Brasil ou, ainda, boas condições para experimentos em campo. Mas, em conjunto com os isótopos estáveis, configuram perspectivas importantes para incrementar nosso conhecimento sobre a ecologia de peixes de riacho. Especialmente nos riachos tropicais, para os quais os escassos estudos apontam alguns resultados contrastantes com os de ambientes temperados, onde a maior parte da literatura sobre o funcionamento das teias tróficas tem sido produzida. Uma vez que interações tróficas são mediadores chave da dinâmica de comunidades e funcionamento dos ecossistemas, este conhecimento torna-se cada vez mais fundamental em um mundo em mudanças, onde estes ambientes vulneráveis vêm sofrendo impactos crescentes resultantes de distúrbios em várias escalas. 


\section{AGRADECIMENTOS}

Agradecemos aos dois revisores anônimos pelas contribuições para a melhoria do manuscrito.

\section{REFERÊNCIAS}

Anjos, M. B. 2013. Fontes autotróficas de energia para a ictiofauna de riachos de floresta de terra firme pertencentes à bacia de drenagem do rio Preto da Eva, Amazonas, Brasil. Tese de Doutorado. INPA/PPG-BADPI. p. 87.

Bastos, R. F., Corrêa, F., Winemiller, K. O., \& Garcia, A. M. 2017. Are you what you eat? Effects of trophic discrimination factors on estimates of food assimilation and trophic position with a new estimation method. Ecological Indicators, 75, 234-241. DOI:10.1016/j.ecolind.2016.12.007

Bearhop, S., Adams, C. E., Waldron, S., Fuller, R. A., \& Macleod, H. 2004. Determining trophic niche width: A novel approach using stable isotope analysis. Journal of Animal Ecology, 73(5), 10071012. DOI:10.1111/j.0021-8790.2004.00861.x

Boecklen, W. J. 2011. Use of stable isotopes in foraging ecology and food web analysis. Annual Review of Ecology, Evolution, and Systematics, 42, 411-440. DOI:10.1146/annurevecolsys-102209-144726

Boëchat, I.G., Krüger, A., Giani, A., Figueredo, C.C., \& Gücker, B. 2011. Agricultural landuse affects the nutritional quality of stream microbial communities. FEMS Microbiology Ecology 77(3), 568-576. DOI:10.1111/j.15746941.2011.01137.x

Bonato, K. O., Burress, E. D., Fialho, C. B., \& Armbruster, J. W. 2018. Resource partitioning among syntopic Characidae corroborated by gut content and stable isotope analyses. Hydrobiologia, 805, 311-324. DOI:10.1007/ s10750-017-3314-0

Brett, M. T., Bunn, S. E., Chandra, S., Galloway, A. W. E., Guo, F., Kainz, M. J., Kankaala, P., Lau, D. C. P., Moulton, T. P., Power, M. E., Rasmussen, J. B., Taipale, S. J., Thorp, J. H., \& Wehr, J. D. 2017. How important are terrestrial organic carbon inputs for secondary production in freshwater ecosystems? Freshwater Biology, 62, 833-853. DOI:10.1111/fwb.12909

Brett, M.T., Holtgrieve, G.W., \& Schindler, D.E. 2018. An assessment of assumptions and uncertainty in deuterium-based estimates of terrestrial subsidies to aquatic consumers. Ecology, 99(5), 1073-1088. DOI: 10.1002/ecy.2211

Brett, M.T., \& Müller-Navarra, D. 1997. The role of highly unsaturated fatty acids in aquatic food web processes. Freshwater Biology 38(3), 483499

Brito, E. F., Moulton, T. P., De Souza, M. L., \& Bunn, S. E. 2006. Stable isotope analysis indicates microalgae as the predominant food source of fauna in a coastal forest stream, southeast Brazil. Austral Ecology, 31(5), 623-633. DOI:10.1111/j.1442-9993.2006.01610.x

Bunn, S. E., Davies, P. M., \& Mosisch, T. D. 1999. Ecosystem measures of river health and their response to riparian and catchment degradation. Freshwater Biology, 41(2), 333345. DOI:10.1046/j.1365-2427.1999.00434.x

Cashman, M. J., Wehr, J.D., \& Truhn, K. 2013. Elevated light and nutrients alter the nutritional quality of stream periphyton. Freshwater Biology 58(7), 1447-1457. DOI:10.1111/fwb.12142

Carvalho, D. R., Castro, D., Callisto, M., Moreira, M. Z., \& Pompeu, P. S. 2015. Isotopic variation in five species of stream fishes under the influence of different land uses. Journal of Fish Biology, 87(3), 559-578. DOI:10.1111/jfb.12734

Carvalho, D. R., Castro, D., Callisto, M., Moreira, M. Z., \& Pompeu, P. S. 2017. The trophic structure of fish communities from streams in the Brazilian Cerrado under different land uses: an approach using stable isotopes. Hydrobiologia, 795, 199-217. DOI:10.1007/s10750-017-3130-6

Carvalho, D. R., Castro, D. M. P., Callisto, M., Chaves, A. J. de M., Moreira, M. Z., \& Pompeu, P. S. 2019. Stable isotopes and stomach content analyses indicate omnivorous habits and opportunistic feeding behavior of an invasive fish. Aquatic Ecology, 53, 365-381.

Carvalho, D. R., Alves, C. B. M., Flecker, A. S., Sparks, J. P., Zacharias Moreira, M., \& Pompeu, P. S. 2020. Using $\delta 15 \mathrm{~N}$ of periphyton and fish to evaluate spatial and seasonal variation of anthropogenic nitrogen inputs in a polluted Brazilian river basin. Ecological Indicators, 115(2020), 106372, DOI:10.1016/j. ecolind.2020.106372

Collins, S. M., Kohler, T. J., Thomas, S. A., Fetzer, W. W., \& Flecker, A. S. 2016a. The importance of terrestrial subsidies in stream food webs varies 
along a stream size gradient. Oikos, 125(5), 674-685. DOI:10.1111/oik.02713

Collins, S. M., Sparks, J. P., Thomas, S. A., Wheatley, S. A., \& Flecker, A. S. 2016b. Increased Light Availability Reduces the Importance of Bacterial Carbon in Headwater Stream Food Webs. Ecosystems, 19(3), 396-410. DOI:10.1007/ s10021-015-9940-3

Collins, S. M., Thomas, S. A., Heatherly, T., MacNeill, K. L., Leduc, A. O. H. C., LópezSepulcre, A., Lamphere, B. A., El-Sabaawi, R. W., Reznick, D. N., Pringle, C. M., \& Flecker, A. S. 2016c. Fish introductions and light modulate food web fluxes in tropical streams: A wholeecosystem experimental approach. Ecology, 97(11), 3154-3166. DOI:10.1002/ecy.1530

Dekar, M. P., King, R. S., Back, J. A., Whigham, D. F., \&Walker, C. M.2012.Allochthonous inputs from grass-dominated wetlands support juvenile salmonids in headwater streams: Evidence from stable isotopes of carbon, hydrogen, and nitrogen. Freshwater Science, 31 (11), 121-132. DOI:10.1899/11-016.1

Doucett, R. R., Marks, J. C., Blinn, D. W., Caron, M., \& Hungate, B. A. 2007. Measuring terrestrial subsidies to aquatic food webs using stable isotopes of hydrogen. Ecology, 88(6), 1587-1592. DOI:10.1890/06-1184

Ebm, N., Guo, F., Brett, M. T., Bunn, S. E., \& Kainz, M. J. 2020. Polyunsaturated fatty acids in fish tissues more closely resemble algal than terrestrial diet sources. Hydrobiologia, 848(2), 371-383. DOI:10.1007/s10750-020-04445-1

El-Sabaawi, R. W., Zandonà, E., Kohler, T. J., Marshall, M. C., Moslemi, J. M., Travis, J., López-Sepulcre, A., Ferriere, R., Pringle, C.M., Thomas, S.A., \& Reznick, D.N. 2012. Widespread intraspecific organismal stoichiometry among populations of the Trinidadian guppy. Functional Ecology 26 (3), 666-676.

Elser, J. J., Fagan, W. F., Denno, R. F., Dobberfuhl, D. R., Folarin, A., Huberty, A., Interlandi, S., Kilham, S. S., McCauley, E., Schulz, K. L. \& Siemann, E. H. 2000. Nutritional constraints in terrestrial and freshwater food webs. Nature 408(6812), 578-580. DOI:10.1038/35046058

Esteves, K. E., Aranha, J. M., \& Albrecht, M. P. 2021. Ecologia trófica de peixes de riachos. Oecologia Australis, 25(2), 266-282. DOI: 10.4257/ oeco.2021.2502.04
Frost, P. C., Benstead, J. P., Cross, W. F., Hillebrand, H., Larson, J. H., Xenopoulos, M. A., \& Yoshida, T. 2006. Threshold elemental ratios of carbon and phosphorus in aquatic consumers. Ecology Letters, 9(7), 774-779. DOI:10.1111/j.14610248.2006.00919.x

Fry, B. 2006. Stable Isotope Ecology. New York: Springer: p. 308. DOI:10.1007/0-387-33745-8

Fujibayashi, M., Miura, Y., Suganuma, R., Takahashi, S., Sakamaki, T., Miyata, N., \& Kazama, S. 2019. Origin of carbon and essential fatty acids in higher trophic level fish in headwater stream food webs. Biomolecules, 9(9), 1-13. DOI:10.3390/biom9090487

Gomes, A. D., Tolussi, C. E., Boëchat, I. G., Pompêo, M. L. M., Cortez, M. P. T., Honji, R. M., \& Moreira, R. G. 2016. Fatty acid composition of tropical fish depends on reservoir trophic status and fish feeding habit. Lipids, 51(10), 1193-1206. DOI:10.1007/s11745-016-4196-z

Guo, F., Bunn, S. E., Brett, M. T., \& Kainz, M. J. 2017. Polyunsaturated fatty acids in stream food webs - high dissimilarity among producers and consumers. Freshwater Biology, 62(8), 1325-1334. DOI:10.1111/fwb.12956

Guo, F., Kainz, M. J., Sheldon, F., \& Bunn, S. E. 2016. The importance of high-quality algal food sources in stream food webs - current status and future perspectives. Freshwater Biology, 61, 815-831. DOI:10.1111/fwb.12755

Hamilton, S. K., Sippel, S. J., \& Bunn, S. E. 2005. Separation of algae from detritus for stable isotope or ecological stoichiometry studies using density fractionation in colloidal silica. Limnology and Oceanography: Methods, 3, 149-157.

Hayden, B., McWilliam-Hughes, S. M., \& Cunjak, R. A. 2016. Evidence for limited trophic transfer of allochthonous energy in temperate river food webs. Freshwater Science, 35(2), 544-558. DOI:10.1086/686001.

Hayden, B., Tongnunui, S., Beamish, F. W. H., Nithirojpakdee, P., Soto, D. X., \& Cunjak, R. A. 2021. Functional and trophic diversity of tropical headwater stream communities inferred from carbon, nitrogen and hydrogen stable isotope ratios. Food webs 26(2021), e00181. DOI10.1016/j.fooweb.2020.e00181

Hondula, K. L., Pace, M. L., Cole, J. J., \& Batt, R. D. 2014. Hydrogen isotope discrimination in 
aquatic primary producers: Implications for aquatic food web studies. Aquatic Sciences, 76(2), 217-229. DOI:10.1007/s00027-013-0331-6

Hotchkiss, E. R., \& Hall, R. O. 2015. Whole-stream ${ }^{13} \mathrm{C}$ tracer addition reveals distinct fates of newly fixed carbon. Ecology, 96(2), 403-416. DOI:10.1890/14-0631.1

Hutchinson G. E. 1978. An introduction to population biology. New Haven, CT: Yale University Press.

Ishikawa, N., Doi, H., \& Finlay, J. 2012. Global metaanalysis for controlling factors on carbon stable isotope ratios of lotic periphyton. Oecologia. 170(2), 541-549.

Ishikawa, N. F., Finlay, J. C., Uno, H., Ogawa, N. O., Ohkouchi, N., Tayasu, I., \& Power, M. E. 2020. Combined use of radiocarbon and stable carbon isotopes for the source mixing model in a stream food web. Limnology and Oceanography, 65(11), 2688-2696. DOI:10.1002/ lno.11541

Jackson, A. L., Inger, R., Parnell, A. C., \& Bearhop, S. 2011. Comparing isotopic niche widths among and within communities: SIBER Stable Isotope Bayesian Ellipses in R. Journal of Animal Ecology, 80(3), 595-602. DOI:10.1111/ j.1365-2656.2011.01806.x

Lau, D.C.P., Leung, K.M.Y., \& Dudgeon, D. 2009. Are autochthonous foods more important than allochthonous resources to benthic consumers in tropical headwater streams? Journal of the North American Benthological Society, 28(2), 426-439. DOI:10.1899/07-079.1

Layman, C. A., Araujo, M. S., Boucek, R., Hammerschlag-Peyer, C. M., Harrison, E., Jud, Z. R., Matich, P., Rosenblatt, A. E., Vaudo, J. J., Yeager, L. A., Post, D. M., \& Bearhop, S. 2012. Applying stable isotopes to examine food-web structure: An overview of analytical tools. Biological Reviews, 87(3), 545-562. DOI: 10.1111/j.1469-185X.2011.00208.x

Layman, C. A., Arrington, D. A., Mntaña, C. G., \& Post, D. M. 2007a. Can stable isotope ratios provide for community-wide measures of trophic structure? Ecology, 88(1), 42-48. DOI:10.1890/0012-9658(2007)88

Layman, C. A., Quattrochi, J. P., Peyer, C. M., \& Allgeier, J. E. 2007b. Niche width collapse in a resilient top predator following ecosystem fragmentation. Ecology Letters, 10, 937-944.
Martínez Del Rio, C., Wolf, N., Carleton, S. A., \& Gannes, L. Z. 2009. Isotopic ecology ten years after a call for more laboratory experiments. Biological Reviews, 84(1), 91-111. DOI:10.1111/ j.1469-185X.2008.00064.x

Moore, J. W., Semmens, B. X. 2008. Incorporating uncertainty and prior information into stable isotope mixing models. Ecology Letters 11(5), 470-480.

Moulton, T. P., Souza, M. L., Walter, T. L., \& Krsulovic, F. A. M. 2009. Pattern of periphyton chlorophyll and dry mass in a neotropical stream: a cheap and rapid analysis using a hand-held fluorometer. Marine and Freshwater Research, 60, 224-233.

McCutchan Jr, J. H., Lewis Jr, W. M., Kendall, C., \& McGrath, C. C. 2003. Variation in trophic shift for stable isotope ratios of carbon, nitrogen, and sulfur. Oikos, 102, 378-390. DOI:10.1034/ j.1600-0706.2003.12098.x

Neres-Lima, V., Brito, E. F., Krsulović, F. A. M., Detweiler, A. M., Hershey, A. E., \& Moulton, T. P. 2016. High importance of autochthonous basal food source for the food web of a Brazilian tropical stream regardless of shading. International Review of Hydrobiology, 101(34), 132-142. DOI:10.1002/iroh.201601851

Neres-Lima, V., Machado-Silva, F., Baptista, D. F., Oliveira, R. B. S., Andrade, P. M., Oliveira, A. F., Sasada-Sato, C. Y., Silva-Junior, E. F., Feijó-Lima, R., Angelini, R., Camargo, P. B., \& Moulton, T. P. 2017. Allochthonous and autochthonous carbon flows in food webs of tropical forest streams. Freshwater Biology, 62(6), 1-12. DOI:10.1111/fwb.12921

Newsome, S. D., Martinez del Rio, C., Bearhop, S., \& Phillips, D. L. 2007. A niche for isotopic ecology. Frontiers in Ecology and the Environment, 5(8), 429-436. DOI:10.1890/060150.1

Newsome, S. D., Wolf, N., Bradley, C. J., \& Fogel, M.L. 2017. Assimilation and isotopic discrimination of hydrogen in tilapia: Implications for studying animal diet with $\delta^{2} \mathrm{H}$. Ecosphere, 8(1). DOI:10.1002/ecs2.1616

Nielsen, J. M., Clare, E. L., Hayden, B., Brett, M. T., \& Katrina, P. 2018. Diet tracing in ecology: method comparison and selection. Methods in Ecology and Evolution, 9(2), 278-291.

Parnell, A. C., Inger, R., Bearhop, S., \& Jackson, A. L. 2010. Source partitioning using stable isotopes: 
Coping with too much variation. PLoS O, 5(3), e9672.

Parnell, A. C. 2020. simmr: A Stable Isotope Mixing Model. R package version 0.4.2. https:// CRAN.R-project.org/package $=$ simmr

Parzanini, C., Colombo, S.M., Kainz, M.J., Wacker, A., Parrish, C.C., \& Arts, M.T. 2020. Discrimination between freshwater and marine fish using fatty acids: ecological implications and future perspectives. Environmental Reviews, 28(4), 546-559. DOI:10.1139/er-20200031

Post, D. M. 2002. Using stable isotopes to estimate trophic position: model, methods, and assumptions. Ecology, 83(3), 703-718. DOI:10.1890/0012-9658(2002)083[0703:USITET] 2.0.CO;2

Raubenheimer, D., \& Simpson, S. J. 1993. The geometry of compensatory feeding in the locust. Animal Behavior, 45(5), 953-963.

Reis, A. S., Albrecht, M. P., \& Bunn, S. E. 2020. Food web pathways for fish communities in small tropical streams. Freshwater Biology, 65(5), 893-907. DOI:10.1111/fwb.13471

Sacramento, P. A., Manetta, G. I., \& Benedito, E.

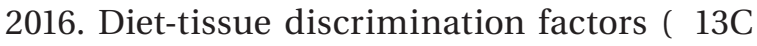
and $\otimes 15 \mathrm{~N}$ ) and turnover rate in somatic tissues of a neotropical detritivorous fish on C3 and C4 diets. Journal of Fish Biology, 89(1), 213-219. DOI:10.1111/jfb.12859

Shipley, O. N., \& Matich, P. 2020. Studying animal niches using bulk stable isotope ratios: an updated synthesis. Oecologia, 193(1), 27-51. DOI:10.1007/s00442-020-04654-4

Simpson, S. J., \& Raubenheimer, D. 2012. The Nature of Nutrition: A Unifying Framework From Animal Adaptation to Human Obesity. Princenton University Press.

Solomon, C. T., Cole, J. J., Doucett, R. R., Pace, M. L., Preston, N. D., Smith, L. E., \& Weidel, B. C. 2009. The influence of environmental water on the hydrogen stable isotope ratio in aquatic consumers. Oecologia, 161(2), 313-324. DOI:10.1007/s00442-009-1370-5

Soto, D. X., Wassenaar, L. I., \& Hobson, K. A. 2013. Stable hydrogen and oxygen isotopes in aquatic food webs are tracers of diet and provenance. Functional Ecology, 27(2), 535543. DOI:10.1111/1365-2435.12054

Stock, B. C., Jackson, A. L., Ward, E. J., Parnell, A. C.,
Phillips, D. L., \& Semmens, B. X. 2018. Analyzing mixing systems using a new generation of Bayesian tracer mixing models. PeerJ, 2018(6), 1-27. DOI:10.7717/peerj.5096

Twining, C. W., Taipale, S. J., Ruess, L., Bec, A., Martin-Creuzburg, D., \& Kainz, M. J. 2020. Stable isotopes of fatty acids: current and future perspectives for advancing trophic ecology. Philosophical Transactions of the Royal Society of London. Series B, Biological Sciences, 375(1804), 20190641. DOI:10.1098/ rstb.2019.0641

Vander Zanden, H. B., Soto, D. X., Bowen, G. J., \& Hobson, K. A. 2016. Expanding the isotopic toolbox: Applications of hydrogen and oxygen stable isotope ratios to food web studies. Frontiers in Ecology and Evolution, 4, 1-19. DOI:10.3389/fevo.2016.00020

Vander Zanden, M. J., \& Rasmussen, J. B. 1999. Primary Consumer $\delta^{13} \mathrm{C}$ and $\delta^{15} \mathrm{~N}$ and the Trophic Position of Aquatic Consumers. Ecology, 80(4), 1395-1404. DOI:10.1890/00129658(1999)080[1395:PCCANA]2.0.CO;2

Vanderklift, M. A., \& Ponsard, S. 2003. Sources of variation in consumer-diet $\delta^{15} \mathrm{~N}$ enrichment: A meta-analysis. Oecologia, 136(2), 169-182. DOI:10.1007/s00442-003-1270-z

Whiteman, J. P., Smith, E. A. E., Besser, A. C., \& Newsome, S. D. 2019. A guide to using compound-specific stable isotope analysis to study the fates of molecules in organisms and ecosystems. Diversity, 11(1). DOI:10.3390/ d11010008

Wilkinson, G. M., Cole, J. J., \& Pace, M. L. 2015. Deuterium as a food source tracer: sensitivity to environmental water, lipid content, and hydrogen exchange. Limnology and Oceanography: Methods, 13 (5), 213-223. DOI: 10.1002/lom3.10019

Zandonà, E., Dalton, C. M., El-Sabaawi, R. W., Howard, J. L., Marshall, M. C., Kilham, S. S., Reznick, D. N., Travis, J., Kohler, T. J., Flecker, A. S., Thomas, S. A., \& Pringle, C. M. 2017. Population variation in the trophic niche of the Trinidadian guppy from different predation regimes. Scientific Reports, 7(1), 1-11. DOI:10.1038/s41598-017-06163-6

Zandonà, E., Oliveira-Cunha, P., \& MoreiraFerreira, B. 2021. O papel dos peixes na reciclagem de nutrientes em riachos tropicais. 
300 | Isótopos estáveis na ecologia de peixes de riacho

Oecologia Australis, 25(2), 450-465. DOI: 10.4257/oeco.2021.2502.14

Zeug, S. C., \& Hoeinghaus, D. J. 2008. Can Stable Isotope Ratios Provide for Community-Wide Measures of Trophic Structure? Ecology, 89(8), 2353-2357.

Submitted: 30 November 2020 Accepted: 24 April 2021 Associate Editors: Erica Caramaschi, Rosana Mazzoni and Rafael Leitão 